\title{
Perfil eletrolítico e peso corporal em suínos submetidos a dietas com diferentes teores de fósforo
}

\author{
Waleska de Melo Ferreira Dantas ${ }^{(1)}$, José Dantas Ribeiro Filho ${ }^{(1)}$, José Domingos Guimarães ${ }^{(1)}$, \\ Sheila Kreutzfeld Farias ${ }^{(1)}$,Simone Eliza Facioni Guimarães ${ }^{(2)}$, Alysson Saraiva(2) e Tânia Toledo de Oliveira(3)
}

(1)Universidade Federal de Viçosa (UFV), Avenida Peter Henry Rolfs, s/noo, Campus Universitário, Departamento de Veterinária, CEP 36570-000 Viçosa, MG. E-mail: wafedantas@yahoo.com.br, dantas@ufv.br, jdguima@ufv.br, sheilakfarias@yahoo.com.br(2)UFV, Departamento de Zootecnia. E-mail: sfacioni@ufv.br, alysson_zoo@yahoo.com.br ${ }^{(3)}$ UFV, Departamento de Bioquímica e Biologia Molecular. E-mail: ttoledo@ufv.br

Resumo - O objetivo deste trabalho foi avaliar o efeito de dietas, com diferentes teores de fósforo, no perfil eletrolítico sanguíneo e no ganho de peso corporal em suínos. Foram utilizados 60 suínos híbridos comerciais, machos castrados, com peso corporal médio inicial de $61,07 \pm 0,86 \mathrm{~kg}$, com aproximadamente 110 dias de idade. Os animais foram distribuídos em blocos ao acaso, com 5 tratamentos e 12 repetições cada um. Os tratamentos foram constituídos de dietas com 0,135, 0,200, 0,265, 0,330 e 0,395\% de fósforo disponível. No início e no final do período experimental, foi determinado o peso corporal e foram coletadas amostras de sangue, sem jejum dos animais, para a mensuração de sódio, potássio, cloreto, magnésio total, fósforo e cálcio ionizado. Observou-se resposta quadrática do peso corporal, de acordo com os tratamentos, e das concentrações séricas de fósforo, magnésio total e cálcio iônico em decorrência dos tratamentos. O ganho de peso corporal foi maior nos animais alimentados com suplementação de fósforo em teores acima de $0,135 \%$. O melhor resultado foi obtido com a dieta de $0,330 \%$ de fósforo, porém, o aumento a partir de $0,200 \%$ na dieta ocasionou elevação na concentração sérica de fósforo.

Termos para indexação: bioquímica clínica, desempenho, exigência nutricional, leitões.

\section{Electrolytic profile and body weight in pigs subjected to diets enriched with different levels of phosphorus}

\begin{abstract}
The objective of this work was to evaluate the effect of diets containing different levels of phosphorus on blood electrolytic profile and on body weight gain in pigs. Sixty hybrid pigs were used, all barrows, with initial body weight of $61.07 \pm 0.86 \mathrm{~kg}$ and about 110 days old. The animals were distributed in a randomized block design, in 5 treatments, with 12 replicates each. The treatments consisted of diets containing 0.135 , $0.200,0.265,0.330$ and $0.395 \%$ available phosphorus. At the beginning and at the end of the experiment, body weight was determined and blood samples were collected, in the animals without fasting, to measure sodium, potassium, chloride, total magnesium, phosphorus and ionized calcium. A quadratic response in body weight was observed, according to treatments, and for serum phosphorus, total magnesium and ionized calcium in the treatments. Weight gain was higher in animals fed with phosphorus supplementation in levels above $0.135 \%$. The best result occurred with $0.330 \% \mathrm{P}$ supplementation, however, an increase from $0.200 \%$ in the diet caused an elevation in phosphorus serum concentration.
\end{abstract}

Index terms: clinical biochemistry, performance, nutritional requirement, piglets.

\section{Introdução}

As exigências nutricionais dos suínos variam de acordo com o potencial genético, a idade, o sexo, o peso e a fase produtiva em que os animais se encontram. A escolha dos ingredientes e a proporção com que cada um participa na ração dependem do balanceamento do nutriente desejado (Zardo \& Lima, 1999).
Nos suínos em crescimento, o processo metabólico mais importante é a retenção de nitrogênio, representada pela deposição de carne magra na carcaça (Lehninger et al., 2002; Abreu et al., 2007). O fósforo tem um papel fundamental nesse processo: gerar energia, em forma de ATP (Gibney et al., 2006). Os alimentos de origem vegetal não contêm fósforo digestível suficiente para a produção

Pesq. agropec. bras., Brasília, v.45, n.10, p.1205-1210, out. 2010 
animal. Por essa razão, o fósforo inorgânico é adicionado às dietas dos animais (Tejedor et al., 2001).

O fósforo representa de 20 a $50 \%$ dos custos com suplementos minerais e vitamínicos e até $1,5 \%$ dos gastos com alimentação de suínos (Teixeira et al., 2004a). Saraiva et al. (2009) realizaram um estudo com suínos em crescimento, com 15 a $30 \mathrm{~kg}$, a fim de verificar a melhor concentração de fósforo na dieta, e observaram melhores resultados nos animais que receberam dietas com 0,509 e $0,477 \%$, respectivamente, de fósforo disponível. Os exames bioquímicos e o perfil metabólico têm sido utilizados na avaliação do balanço nutricional dos rebanhos, uma vez que, em algumas situações, os desequilíbrios nutricionais podem influir nas concentrações de constituintes sanguíneos (Payne \& Payne, 1987).

O alto nível metabólico dos animais geneticamente selecionados para crescimento rápido, requer ajustes nas formulações modernas, para melhor adequar as dietas às necessidades dos animais de forma a garantir máximo desempenho. Esses detalhes poderão ser o diferencial para obtenção de melhores índices zootécnicos e tornar a suinocultura brasileira cada vez mais competitiva (Savaris et al., 2006).

Não foram encontradas na literatura informações sobre os teores de fósforo adequados para cada faixa etária de suínos melhorados geneticamente e, tampouco, de implicações desses teores sobre a homeostase.

O objetivo deste trabalho foi avaliar o efeito de dieta, com diferentes teores de fósforo no perfil eletrolítico sanguíneo e no ganho de peso corporal de suínos híbridos comerciais.

\section{Material e Métodos}

Foram utilizados 60 suínos híbridos comerciais, machos castrados, com peso corporal médio inicial de $61,07 \pm 0,86 \mathrm{~kg}$ e aproximadamente 110 dias de idade, provenientes do cruzamento de fêmeas Topigs (Large White x Landrace x Pietrain) (Topigs do Brasil Ltda., Campinas, SP).

O experimento foi conduzido na granja de suínos da Fazenda Experimental Vale do Piranga, de propriedade da Epamig, no Município de Oratórios, MG, entre julho e agosto de 2008.

Utilizou-se o delineamento experimental de blocos ao acaso, com 5 tratamentos e 12 repetições com dois animais por unidade experimental. Os animais foram alojados em galpão de alvenaria com piso de concreto e telhado de amianto, com 40 baias para dois animais adultos cada, que corresponde a uma lotação de $1,9 \mathrm{~m}^{2}$ por animal, equipadas com bebedouros do tipo chupeta e comedouros semiautomáticos.

As condições ambientais no interior das baias foram monitoradas diariamente, por meio de termômetros de bulbo seco e úmido. Os animais receberam as rações experimentais e água à vontade (Tabela 1). Durante o período experimental, a média das temperaturas

Tabela 1. Composição percentual e calculada das rações experimentais.

\begin{tabular}{|c|c|c|c|c|c|}
\hline \multirow[t]{2}{*}{ Ingrediente (\%) } & \multicolumn{5}{|c|}{ Teores de fósforo total (\%) } \\
\hline & 0,410 & 0,475 & 0,540 & 0,605 & 0,670 \\
\hline Milho grão & 68,977 & 68,977 & 68,977 & 68,977 & 68,977 \\
\hline Farelo soja & 26,236 & 26,236 & 26,236 & 26,236 & 26,36 \\
\hline Óleo soja & 0,927 & 0,927 & 0,927 & 0,927 & 0,927 \\
\hline Fosfato bicálcico & 0,000 & 0,351 & 0,703 & 1,054 & 1,405 \\
\hline Calcário & 1,130 & 0,369 & 0,618 & 0,458 & 0,369 \\
\hline Inerte & 1,500 & 1,373 & 1,246 & 1,119 & 0,856 \\
\hline Sal comum & 0,381 & 0,381 & 0,381 & 0,381 & 0,381 \\
\hline L-lisina-HCl & 0,302 & 0,302 & 0,302 & 0,302 & 0,302 \\
\hline L-treonina & 0,088 & 0,088 & 0,088 & 0,088 & 0,088 \\
\hline Vitcre - Sui ${ }^{(1)}$ & 0,200 & 0,200 & 0,200 & 0,200 & 0,200 \\
\hline $\operatorname{Min}-\operatorname{Sui}^{(2)}$ & 0,100 & 0,100 & 0,100 & 0,100 & 0,100 \\
\hline Sulfato de colistina ${ }^{(3)}$ & 0,050 & 0,050 & 0,050 & 0,050 & 0,050 \\
\hline DL-Metionina & 0,099 & 0,099 & 0,099 & 0,099 & 0,099 \\
\hline BHT & 0,010 & 0,010 & 0,010 & 0,010 & 0,010 \\
\hline Total & 100,00 & 100,00 & 100,00 & 100,00 & 100,00 \\
\hline \multicolumn{6}{|l|}{ Composição calculada $^{(4)}$} \\
\hline EM $\left(\mathrm{kcal} \mathrm{kg}^{-1}\right)$ & 3.230 & 3.230 & 3.230 & 3.230 & 3.230 \\
\hline Proteína bruta (\%) & 18,00 & 18,00 & 18,00 & 18,00 & 18,00 \\
\hline Lisina digestível (\%) & 1,036 & 1,036 & 1,036 & 1,036 & 1,036 \\
\hline Met.+cist. digestível (\%) & 0,622 & 0,622 & 0,622 & 0,622 & 0,622 \\
\hline Treonina digestível (\%) & 0,673 & 0,673 & 0,673 & 0,673 & 0,673 \\
\hline Triptofano digestível (\%) & 0,186 & 0,186 & 0,186 & 0,186 & 0,186 \\
\hline Valina digestível (\%) & 0,745 & 0,745 & 0,745 & 0,745 & 0,745 \\
\hline Sódio (\%) & 0,170 & 0,170 & 0,170 & 0,170 & 0,170 \\
\hline Cálcio (\%) & 0,518 & 0,518 & 0,518 & 0,518 & 0,518 \\
\hline $\mathrm{P}$ total $(\%)$ & 0,410 & 0,475 & 0,540 & 0,605 & 0,670 \\
\hline P disponível (\%) & 0,135 & 0,200 & 0,265 & 0,330 & 0,395 \\
\hline
\end{tabular}

(1)Supermix Nutrição Animal Ltda. (Ponte Nova, MG). Conteúdo por quilograma de produto: vitamina A(3.000.000 UI); vitamina D3 (1.200.000 UI); vitamina E (7.500 mg); vitamina K (1.250 mg); vitamina B12 (7000 mg); vitamina B2 $(2.300 \mathrm{mg})$; biotina $(50 \mathrm{mg})$; pantotenato de Ca $(6.000 \mathrm{mg})$; niacina $(10.000 \mathrm{mg})$; colina (125 g); promotor crescimento (50 g); antioxidante (5.000 mg); vitamina B1 (500 g); vitamina B6 (1.000 mg); acido fólico $(150 \mathrm{mg})$; veículo q.s.p. $(1.000 \mathrm{~g}) .{ }^{(2)}$ Supermix Nutrição Animal Ltda. (Ponte Nova, MG). Conteúdo por quilograma de produto: ferro $(45.000 \mathrm{mg})$; cobre (37.000 mg); manganês (25.000 mg); zinco (35.000 mg); cobalto (300 mg); iodo (800 mg); selênio (120 mg) veículo q.s.p. (1000 g). ${ }^{(3)}$ Princípio ativo: sulfato de colistina. ${ }^{(4)}$ Valores estimados com base nos coeficientes de digestibilidade dos aminoácidos dos ingredientes, de acordo com Rostagno et al. (2005). 
mínima e máxima no interior do galpão foram $8,9 \pm 1,6$ e $24,3 \pm 2,1^{\circ} \mathrm{C}$, respectivamente. A umidade relativa média calculada para o período foi de $71,3 \pm 18,3 \%$. Os tratamentos foram constituídos de uma ração basal, semsuplementação de fósforo, compostaprincipalmente por milho e farelo de soja, suplementada com vitaminas, minerais e aminoácidos. As rações foram formuladas de acordo com as recomendações para leitões de 60 a $90 \mathrm{~kg}$ para todos os nutrientes, segundo Rostagno et al. (2005), exceto o fósforo. As rações correspondentes aos tratamentos experimentais foram suplementadas com quatro níveis de fosfato bicálcico $(0,000 ; 0,315$; 0,703; 1,054 e 1,405\%), em substituição ao caulim e o calcário calcítico, o que produziu rações experimentais com 0,$135 ; 0,200 ; 0,265 ; 0,330$ e $0,495 \%$ de fósforo disponível, tendo sido todas isoproteicas, isoenergéticas e isocálcicas.

Os animais foram pesados, individualmente, no início (M0) e ao final do período experimental (M1) para determinação do ganho de peso corporal. Amostras de sangue foram coletadas nos dois períodos (M0 e M1) por meio de venopunção no sinus orbital com agulhas descartáveis hipodérmicas 40x16, sem jejum prévio. A seguir, as amostras foram acondicionadas em frascos de $10 \mathrm{~mL}$ sem anticoagulante para obtenção de soro. As amostras foram, então, mantidas congeladas a $-20^{\circ} \mathrm{C}$ até o momento das análises laboratoriais.

$\mathrm{Na}$ mensuração do sódio e potássio, foi utilizado espectrofotômetro de chama, Micronal B462 (Micronal S.A., São Paulo, Brasil); para o cloreto, fósforo e magnésio total, as análises foram realizadas por meio de kits comerciais Bioclin (Quibasa, Belo Horizonte, Brasil) com uso de equipamento eletrônico Alizé - Clin line 150 (Lisabio, Pouilli-en-Auxois, França), enquanto o cálcio iônico foi analisado por meio de aparelho de íons seletivo AVL (Roche, São Paulo, Brasil).

As análises referentes aos valores obtidos no início e no final do experimento foram feitas por pareamento e suas médias comparadas pelo teste DMS. Os dados quantitativos foram submetidos aos testes de Lilliefors e Cochran \& Bartlet para verificar a normalidade dos dados e homogeneidade das variâncias, respectivamente. Foi feita a análise de variância e, quando houve significância pelo teste $\mathrm{F}$, as médias foram comparadas pelo teste de Tukey, a 5\% de probabilidade. A análise de regressão foi realizada para todas as características estudadas de acordo com a concentração de fósforo na ração. Empregou-se o programa Saeg-9.0 (Universidade Federal de Viçosa, 2007).

O experimento foi aprovado pelo comitê de Ética do Departamento de Veterinária - Protocolo UFV no $35 / 2009$.

\section{Resultados e Discussão}

Não houve diferença nas concentrações séricas de cloreto, sódio, potássio e magnésio em leitões antes do fornecimento das dietas (M0), mas foram observadas diferenças nas concentrações séricas de fósforo e cálcio iônico, o que demonstra a variação individual entre animais da mesma espécie, e seus valores mantiveramse na faixa de referência (Radostits et al., 2000; Kaneko et al., 2008).

No final da fase experimental (M1), verificouse aumento nos valores séricos de fósforo e no peso corporal, mas houve redução nas concentrações séricas de cálcio iônico, sódio e cloreto (Tabela 2).

Quando foram fornecidas dietas com 0,135, 0,200 e $0,265 \%$ de fósforo, observou-se aumento na concentração sérica das dietas (Figura 1 A). Nos tratamentos com 0,330 e $0,395 \%$ de fósforo, houve estabilização na concentração sérica de fósforo, mesmo com o aumento dos teores de fósforo na dieta. Quando foram comparados os valores de referência, registrados na literatura (Cera \& Mahan, 1988; Kaneko et al., 2008), com os dos tratamentos com 0,200, 0,265, 0,330 e $0,395 \%$ de fósforo disponível, observou-se que as concentrações séricas de fósforo estavam acima dos valores fisiológicos, tendo-se verificado que, à medida que a relação cálcio e fósforo diminuiu na dieta,

Tabela 2. Concentrações séricas de cloreto, fósforo, sódio, potássio, magnésio, cálcio iônico e peso corporal de suínos em crescimento $(60-90 \mathrm{~kg})$ com alto potencial genético antes (M0) e após (M1) serem submetidos as dietas ${ }^{(1)}$.

\begin{tabular}{lrc}
\hline Variável & \multicolumn{1}{c}{$\mathrm{M} 0$} & \multicolumn{1}{c}{$\mathrm{M} 1$} \\
\hline Fósforo $\left(\mathrm{mg} \mathrm{dL}^{-1}\right)$ & $8,65 \pm 1,37 \mathrm{~b}$ & $12,06 \pm 3,96 \mathrm{a}$ \\
Cálcio ionizado $\left(\mathrm{mg} \mathrm{dL}^{-1}\right)$ & $5,01 \pm 0,49 \mathrm{a}$ & $4,52 \pm 0,58 \mathrm{~b}$ \\
Magnésio total $\left(\mathrm{mg} \mathrm{dL}^{-1}\right)$ & $1,81 \pm 0,30 \mathrm{a}$ & $1,79 \pm 0,12 \mathrm{a}$ \\
Sódio $\left(\mathrm{mEq} \mathrm{L}^{-1}\right)$ & $138,13 \pm 8,20 \mathrm{a}$ & $135,23 \pm 8,33 \mathrm{~b}$ \\
Potássio $\left(\mathrm{mEq} \mathrm{L}^{-1}\right)$ & $4,77 \pm 0,55 \mathrm{a}$ & $4,86 \pm 0,49 \mathrm{a}$ \\
Cloreto $\left(\mathrm{mEq} \mathrm{L}^{-1}\right)$ & $105,94 \pm 3,77 \mathrm{~b}$ & $107,14 \pm 12,33 \mathrm{a}$ \\
Peso corporal $(\mathrm{kg})$ & $61,00 \pm 0,93 \mathrm{~b}$ & $92,96 \pm 4,22 \mathrm{a}$ \\
\hline
\end{tabular}

${ }^{(1)}$ Médias, seguidas por letras iguais nas linhas, não diferem entre sí pelo teste DMS, a $5 \%$ de probabilidade. 
houve aumento do fósforo sérico e redução do cálcio iônico sérico. Stewart (1983) observou que o aumento do fosfato no organismo pode ocasionar acidose metabólica. Resultados semelhantes foram obtidos por Koch \& Mahan (1986), Cera \& Mahan (1988) e Arouca et al. (2009). Esses autores também constataram efeito quadrático na concentração de fósforo inorgânico, no soro sanguíneo de suínos em terminação que receberam teores crescentes de fósforo dietético.

A concentração de cálcio ionizado apresentou comportamento quadrático em função dos teores de fósforo na dieta. Foi possível observar redução inicial quando os animais foram submetidos às dietas com 0,200 e $0,265 \%$ de fósforo disponível e posterior estabilização da curva em valores baixos, com pequenos aumentos nos teores de fósforo de $0,330 \mathrm{e}$ 0,395\% (Figura $1 \mathrm{~B}$ ).

As concentrações de cálcio iônico antes do fornecimento das dietas foram maiores em todos os tratamentos (Tabela 2). Conforme descrito na literatura (Cera \& Mahan, 1988; Ketaren et al., 1993; Carter et al., 1996), o excesso de fósforo na dieta pode interferir na absorção de cálcio, e ocasionar alterações na relação $\mathrm{Ca}: \mathrm{P}$. Exemplo desse desequilíbrio ocorre
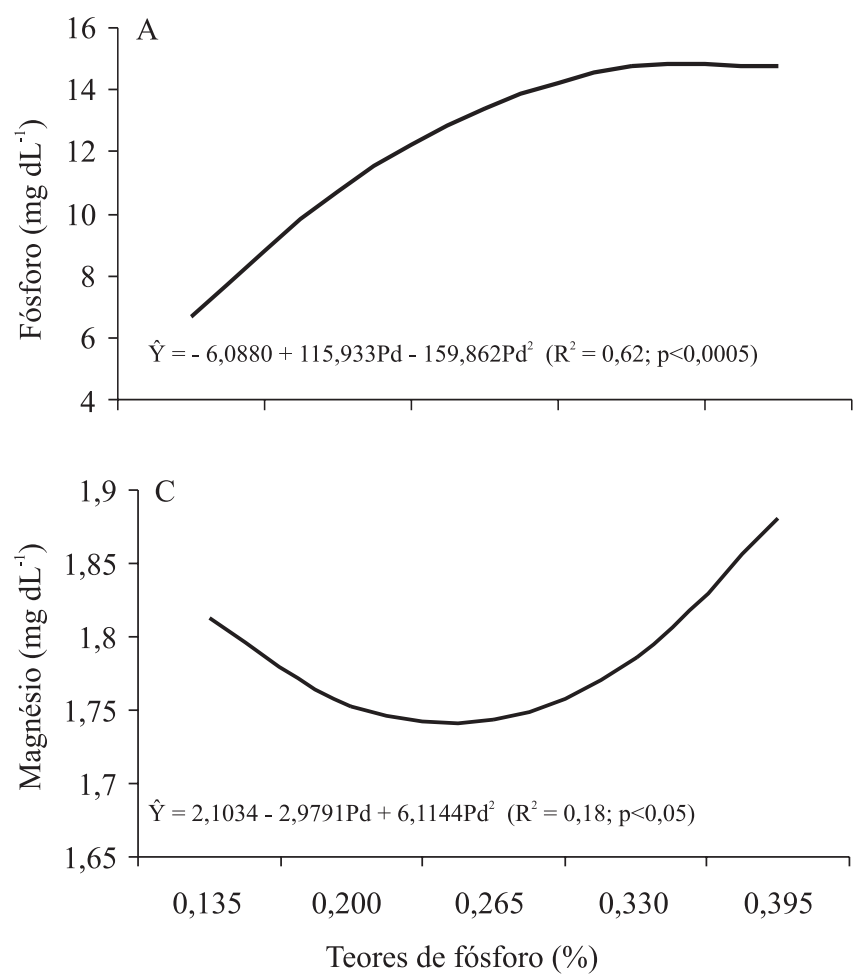

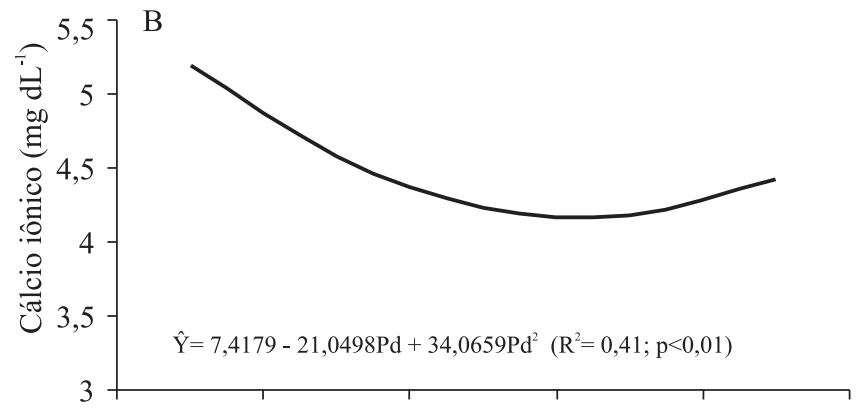

em equinos com osteodistrofia fibrosa, causada pela excessiva oferta e ingestão de alimentos ricos em fósforo (Riet-Correa et al., 1998; Radostits et al., 2000). Ressalta-se que essa enfermidade é também descrita em suínos submetidos a dietas com altos teores de fósforo (Radostits et al., 2000). Entretanto, não foram observados sinais clínicos que caracterizam a osteodistrofia fibrosa nos animais deste ensaio. Dificilmente, mesmo com elevados teores de fósforo na dieta, essa enfermidade se manifestaria, pois as dietas foram utilizadas durante a fase de terminação, que normalmente compreende um período de quatro a seis semanas de duração, insuficiente para o aparecimento da doença. Apesar da diminuição, os valores mantiveram-se na faixa de referência citada na literatura (Radostits et al., 2000). Os menores valores para o cálcio iônico sérico foram verificados nas dietas com $0,265 \%$ de fósforo disponível.

Quanto à concentração de magnésio sérico, também foi observado comportamento quadrático, em função dos níveis de fósforo na dieta (Figura $1 \mathrm{C}$ ). A concentração sérica de magnésio diminuiu nas três primeiras formulações $(0,135,0,200$ e $0,265 \%)$ de fósforo disponível e, posteriormente, elevou-se com

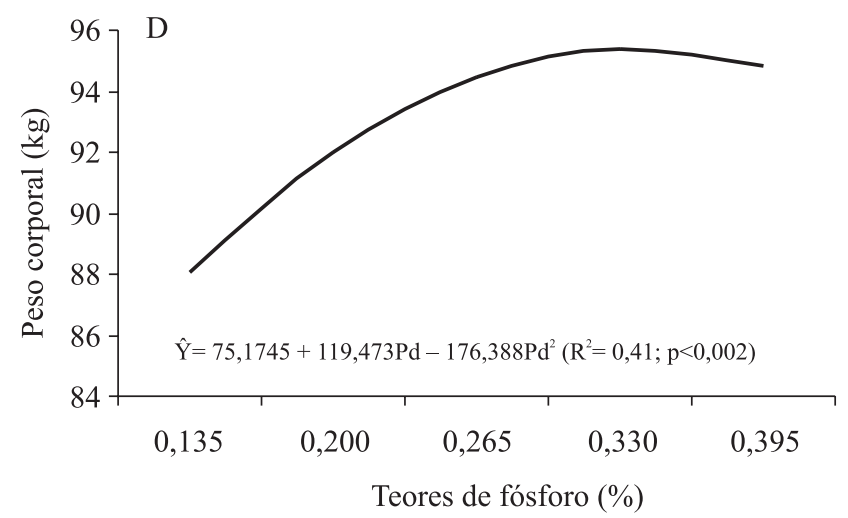

Figura 1. Concentrações séricas de fósforo (A), cálcio iônico (B), magnésio (C) e peso corporal (D) de suínos (60-90 kg) com alto potencial genético em função de diferentes teores de fósforo da dieta. 
o aumento nos teores de fósforo $(0,330$ e 0,395\%). Assim como o cálcio, o magnésio também foi influenciado pela concentração elevada de fósforo, o que corrobora resultados obtidos por Cera \& Mahan (1988). Os referidos autores detectaram diminuição nos valores de magnésio, quando aumentaram os teores de fósforo da dieta. Quando há diminuição do cálcio sérico, usualmente ocorre liberação do paratormônio para atuar nos rins, o que promove a reabsorção do cálcio e, consequentemente, do magnésio (Kaneco et al., 2008).

Apesar das variações, os teores de magnésio também se mantiveram na faixa de referência (Tsutsumi et al., 1999; Radostits et al., 2000). Entretanto, Kaneko et al. (2008) descreveram valores sanguíneos para o magnésio de 2,7 a 3,7 $\mathrm{mg} \mathrm{dL}^{-1}$, o que difere dos obtidos no presente trabalho, enquanto Junqueira (2004) afirmou que teores de magnésio abaixo de $2 \mathrm{mg} \mathrm{dL}^{-1}$ podem indicar deficiência desse eletrólito.

O maior ganho de peso corporal $(34,1 \mathrm{~kg})$ nos animais submetidos aos tratamentos foi verificado com $0,330 \%$ de fósforo disponível na dieta (Figura $1 \mathrm{D}$ ).

O peso corporal apresentou comportamento quadrático em relação às concentrações de fósforo nos diferentes tratamentos. As concentrações de 0,135 e $0,200 \%$ proporcionaram aumentos no ganho de peso, enquanto nas maiores concentrações, 0,265 a 0,395\%, detectou-se redução nesse ganho.

O peso corporal é uma variável que recebe influência direta da alimentação. Para que animais de produção tenham um ganho de peso desejado, é necessária uma dieta balanceada, com ingredientes de boa qualidade, de modo a propiciar melhor conversão alimentar e maior desempenho. Stahly et al. (2000), Hastad et al. (2004), Arouca et al. (2009) e Saraiva et al. (2009) desenvolveram estudos com suínos em crescimento de 15 a $30 \mathrm{~kg}$, e os resultados encontrados estão de acordo com os obtidos no presente trabalho, pois o fósforo está relacionado diretamente à deposição do tecido muscular (geração de ATP) e aos metabolismos energético e celular.

O peso corporal aumentou em decorrência da adição de fósforo, o que mostra a importância desse nutriente na composição da dieta, bem como indica que há necessidade de se revisarem os teores de fósforo nas composições de rações para suínos em crescimento (60-95 kg), constantes das tabelas atuais, embora tenha-se observado redução nas concentrações séricas totais de cálcio iônico e magnésio.

\section{Conclusões}

1. O aumento dos teores de fósforo na dieta ocasiona acréscimo na sua concentração sérica e diminuição nos valores séricos de cálcio iônico e magnésio.

2. O ganho de peso corporal é superior nos animais que recebem dietas suplementadas com fósforo. O melhor resultado no ganho de peso ocorreu com teores de $0,330 \%$ de fósforo disponível.

\section{Agradecimentos}

À Fundação de Amparo à Pesquisa do Estado de Minas Gerais, pelo apoio financeiro da pesquisa.

\section{Referências}

ABREU, M.L.T. de; DONZELE, J.L.; OLIVEIRA, R.F.M. de; OLIVEIRA, A.L.S. de; SANTOS, F. de A.; PEREIRA, A.A. Níveis de lisina digestível em rações, utilizando-se o conceito de proteína ideal, para suínos machos castrados de alto potencial genético para deposição de carne magra na carcaça dos 60 aos $95 \mathrm{~kg}$. Revista Brasileira de Zootecnia, v.36, p.54-61, 2007.

AROUCA, C.L.C.; FONTES, D.O.; SILVA, F.O.C.; FERREIRA, W.M.; SILVA, M. A.; VIDAL, T.Z.B.; CORRÊA, G.S.S.; PAULA, E. Exigência de fósforo disponível para suínos machos castrados selecionados para deposição de carne magra, dos 30 aos $60 \mathrm{~kg}$. Arquivo Brasileiro de Medicina Veterinária e Zootecnia, v.61, p.1094-1103, 2009.

CARTER, S.D.; CROMWELL, G.L.; COMBS, T.R.; COLOMBO, G.; FANTI, P. The determination of serum concentrations of osteocalcin in growing pigs and its relationship to end-measures of bone mineralization. Journal of Animal Science, v.74, p.2719-2729, 1996.

CERA, K.R.; MAHAN, D.C. Effect of dietary calcium and phosphorus level sequences on performance, structural soundness and bone characteristics of growing-finishing swine. Journal of Animal Science, v.66, p.1598-1605, 1988.

GIBNEY, M.J.; MACDONALD, I.A.; ROCHE, H.M. Nutrição e metabolismo. Rio de Janeiro: Guanabara Koogan, 2006. 351p.

HASTAD, C.W.; DRITZ, S.S.; TOKACH, M.D.; GOODBANG, R.D,; NELSSEN, J.L.; DEROUCHEY, J.M.; BOYD, R.D.; JOHNSTON, M.E. Phosphorus requirements of growing-finishing pigs reared in a commercial environment. Journal of Animal Science, v.82, p.2945-2952, 2004.

JUNQUEIRA, O.M. O magnésio na nutrição animal. 2004. Disponível em: <http://www.serrana.com.br/nutricaoanimal/ boletimtecnicointegra.asp?id=62>. Acesso em: 10 mar. 2009 .

KANEKO, J.J.; HARVEY, J.W.; BRUSS, M.L. Clinical biochemistry of domestic animals. 5.ed. San Diego: Academic, 2008. 932p.

KETAREN, P.P.; BATTERHAM, E.S.; WHITE, E.; FARREL, D.J.; MILTHORPE, B.K. Phosphorus studies in pigs. 1. Available

Pesq. agropec. bras., Brasília, v.45, n.10, p.1205-1210, out. 2010 
phosphorus requirements of grower finisher pigs. British Journal of Nutrition, v.70, p.249-268, 1993.

KOCH, M.E.; MAHAN, D.C. Biological characteristics for assessing low phosphorus intake in finishing swine. Journal of Animal Science, v.62, p.163-172, 1986.

LEHNINGER, A.L.; NELSON, D.L.; COX, M.M. Princípios da bioquímica. 3.ed. São Paulo: Sarvier, 2002. 975p.

PAYNE, J.M.; PAYNE, S. The metabolic profile test. New York: Oxford University, 1987. 327p.

RADOSTITS, O.M.; BLOOD, D.C.; GAY, C.C. Veterinary medicine. $8^{\text {th }}$ ed. Rio de Janeiro: Guanabara Koogan, 2000. 1763p.

RIET-CORREA, F.; SOARES, M.P.; MENDEZ, M.D. Intoxicações em equinos no Brasil. Ciência Rural, v.28, p.715-722, 1998.

ROSTAGNO, H.S.; ALBINO, L.F.T.; DONZELE, J.L.; GOMES, P.C.; OLIVEIRA, R.F. de; LOPES, D.C.; FERREIRA, A.S.; BARRETO, S.L.T. Tabelas brasileiras para aves e suínos: composição de alimentos e exigências nutricionais. 2.ed. Viçosa: UFV, 2005. 186p.

SARAIVA, A.; DONZELE, J.L.; OLIVEIRA, R.F.M. de; ABREU, M.L.T. de; SILVA, F.C. de O.; SANTOS, F. de A. Available phosphorus levels in diets for swine from 15 to $30 \mathrm{~kg}$ genetically selected for meat deposition. Revista Brasileira de Zootecnia, v.38, p.307-313, 2009.

SAVARIS, V.D.L.; FERREIRA, R.A.; POOZZA, P.C. Balanço eletrolítico de rações para suínos. 2006. Disponível em: <http:// www.serrana.com.br/nutricaoanimal/boletimtecnicointegra. asp?id=134>. Acesso em: 10 mar. 2009.
STAHLY, T.S.; LUTZ, T.R.; CLAYTON, R.D. Dietary available phosphorus needs of high lean pigs fed from 9 to $119 \mathrm{~kg}$ body weight: ASR-L655. Swine Research Report, p.48-50, 2000. Available at: $<$ http://www.ipic.iastate.edu/reports/00swinereports/ asl-655.pdf> . Accessed on: 20 June 2008.

STEWART, P.A. Modern quantitative acid-base chemistry. Canadian Journal of Physiology and Pharmacology, v.61, p.1444-1461, 1983.

TEIXEIRA, A. de O.; LOPES, D.C.; LOPES, J.B.; SILBER, D.M.; VITTI, D.M.S.S.; GOMES, P.C.; HOSTAGNO, H.S.; MOREIRA, J.A.; INÁCIO, F. Determinação da biodisponibilidade de fósforo de diferentes fontes pela técnica de diluição isotópica, em suínos em crescimento. Revista Brasileira de Zootecnia, v.33, p.1231-1237, 2004a.

TEJEDOR, A.A.; ALBINO, L.F.T.; ROSTAGNO, H.S.; VIEITES, F.M. Efeito da adição da enzima fitase sobre o desempenho e a digestibilidade ileal de nutrientes. Revista Brasileira de Zootecnia, v.30, p.802-808, 2001.

TSUTSUMI, H.; MONNAI, Y.; ISHII, H.; TANIOKA, Y.; TANIGAWA, M. Diurnal variations and effects of fasting on blood constituents in minipigs. Experimentação Animal, v.48, p.247-254, 1999.

UNIVERSIDADE FEDERAL DE VIÇOSA. SAEG Sistema para Análises Estatísticas. Versão 9.1.Viçosa: UFV, 2007. 149p.

ZARDO, A.O.; LIMA, G.M.M. de. Alimentos para suínos. BIPERS, v.8, p.7-71, 1999.

Recebido em 10 de junho de 2010 e aprovado em 14 de setembro de 2010 